\title{
Stage IB Cutaneous Melanoma AJCC v7
}

National Cancer Institute

\section{Source}

National Cancer Institute. Stage IB Cutaneous Melanoma A/CC v7. NCI Thesaurus. Code C86030.

Stage IB includes: (T 1 b, N0, M0); (T 2a, N0, M0). T1 b: Cutaneous melanoma with a tumor measuring $1.0 \mathrm{~mm}$ or less in thickness, with ulceration or mitoses equal or more than 1/mm2. T2a: Cutaneous melanoma with a tumor measuring 1.01-2.0 mm in thickness, without ulceration. N0: No regional lymph node metastases. M0: No detectable evidence of distant metastases. (from AJCC 7th Ed.) 